\title{
Persuasive bodies: Testimonies of deep brain stimulation and Parkinson's on YouTube
}

\author{
John Gardner ${ }^{\mathrm{a}, *}$, Narelle Warren ${ }^{\mathrm{a}}$, Courtney Addison ${ }^{\mathrm{b}}$, Gabby Samuel ${ }^{\mathrm{c}}$ \\ ${ }^{a}$ School of Social Sciences, Monash University, Melbourne, Australia \\ ${ }^{\mathrm{b}}$ Science in Society, Victoria University of Wellington, New Zealand \\ ${ }^{\mathrm{c}}$ Department of Global Health and Social Medicine, Kings College London, UK
}

\section{A R T I C L E I N F O}

\section{Keywords:}

Digital health

Social media

Narrative

Chronic illness

Neurostimulation

Technology

\begin{abstract}
A B S T R A C T
Contemporary publics actively engage with diverse forms of media when seeking health-related information. The hugely popular digital media platform YouTube has become one means by which people share their experiences of healthcare. In this paper, we examine amateur YouTube videos featuring people receiving Deep Brain Stimulation (DBS) for the treatment of Parkinson's disease. DBS has become a widely implemented treatment, and it is surrounded by high expectations that can create difficulty for clinicians, patients and their families. We examine how DBS, Parkinson's disease, and DBS recipients themselves, are delineated within these YouTube videos. The videos, we demonstrate, contain common compositional and stylistic elements that collectively represent DBS as a technological fix, and which accentuate the autonomy of the DBS recipient. The relational, interpersonal dimensions of chronic illness, and the complex impact of DBS on family dynamics, are elided. We therefore shed light on the means by which high expectations regarding DBS are sustained and circulated, and more generally, we illustrate how potentially powerful representations of medical technologies can emerge from the intersection of social media platforms, afflicted bodies and patient narratives.
\end{abstract}

\section{Introduction}

Deep brain stimulation (DBS) has become a widely used therapy for managing the symptoms of Parkinson's disease. It involves direct, ongoing stimulation of specific areas deep within the brain using fully implantable componentry: electrodes are surgically implanted in the target area of the brain, and are connected via a lead that runs from the top of the scalp down the side of the neck, to an implanted pulse generator that is similar in appearance and function to a cardiac pacemaker (Okun, 2014). Well over one hundred thousand people worldwide have been implanted with the DBS system, and it is generally considered to be a clinically-effective and cost-effective means of reducing the oftendebilitating tremor, rigidity and stiffness associated with Parkinson's disease (Pietzsch et al., 2016; Eggington et al., 2014). Many DBS recipients have experienced a dramatic improvement in their day-to-day function, and the therapy is now commissioned by public health services or private health insurers in a number of countries throughout Europe, Asia and Australasia, and North America.

The implementation of DBS however, has been characterised by challenges and tensions. Clinical teams have noted that despite its obvious ameliorative effects on the motor symptoms of Parkinson's, some recipients have not experienced the improvement in the quality of life that would be expected (Schüpbach et al., 2006; Agid et al., 2006; Gilbert, 2018). Several explanations have been provided for this divergence. First, while many recipients have indeed experienced a dramatic improvement in symptoms, many others have had more modest improvements, prompting feelings of disappointment and frustration. Second, as with other neurological interventions, DBS in some cases appears to induce dramatic changes in behaviour, such as mania and impulsivity, which are upsetting for recipients and families. And third, the newfound sense of autonomy experienced by recipients has, in some cases, disrupted spousal relations and family dynamics, resulting in significant emotional strain (Schüpbach et al., 2006; Agid et al., 2006; Gilbert, 2012). In response to these tensions, commentators have emphasised the necessity of managing expectations: potential recipients and their families, it is argued, need to be carefully coached on the likelihood of more modest improvements, and on the potential impact of DBS on family dynamics (Bell et al., 2009; Bell et al., 2011; Gardner and Warren, 2018; Gardner, 2017).

According to such commentary there is, then, a troubling

\footnotetext{
* Corresponding author. W414 Menzies Building, 20 Chancellors Walk, Monash University, Clayton Campus, Wellington Road, Melbourne, VIC 3800, Australia.

E-mail addresses: John.gardner@monash.edu (J. Gardner), Narelle.warren@monash.edu (N. Warren), Courtney.addison@monash.edu (C. Addison), gabrielle.samuel@kcl.ac.uk (G. Samuel).
} 
disjunction between the expectations and hopes of recipients, and the reality of everyday life with DBS. Indeed, recent studies have noted that clinicians themselves feel that managing the expectations of patients and their families is one of their most challenging tasks (Gardner et al., 2015). Potential DBS recipients, it has been noted, often arrive at a service with unrealistic visions of life with DBS, and in some services, considerable time is devoted to prompting recipients to reimagine the likely impact of DBS on their day-to-day life, and to anticipate how they might manage the adverse impact of DBS on family life (Santos et al., 2017).

Commentators have suggested that DBS-related information in the public sphere is a major reason for this disjunction (Racine et al., 2010). Studies have illustrated that, as with many 'high-tech' developments in biomedicine, DBS has been the subject of considerable hype. Print media in particular have been criticised for their tendency to produce 'over-optimistic portrayals of DBS: news media articles have focused on dramatic individual cases, while neglecting to report on the more modest improvements experienced by the majority of recipients (Gilbert and Ovadia, 2011). Racine et al. (2007) have argued that by publicising DBS miracle stories, the news media is, in effect, creating unrealistic expectations among potential DBS recipients and their families, thus placing considerable pressure on clinical teams.

Contemporary publics, however, actively engage with diverse forms of media when seeking information (Wyatt et al., 2013). While traditional forms of media such as print media and television no doubt remain important sources of information, health-seeking individuals also engage with various forms of digital media (Wyatt et al., 2005; Lupton, 2017), particularly social media, that permit users to create and share health-related content. Indeed, a significant number of videos focusing on DBS can now be found on one of the most well-known social media sites: YouTube. Many of these have been posted by DBS recipients or their family members, and some have been watched hundreds of thousands of times. In this paper, we examine the way in which DBS, Parkinson's disease, and also the DBS recipient themselves, are delineated within these YouTube videos. By doing this, we shed light on the means by which expectations and perspectives regarding DBS are sustained and circulated, and more generally, we illustrate how particular, potentially powerful renderings of the individual, illness and medical technologies can emerge from the intersection of social media platforms, afflicted bodies and patient narratives. The DBS-related YouTube videos, we argue, contain common compositional elements that collectively accentuate the autonomy of the DBS recipient, and which present DBS as a technological fix. In the process, the relational, interpersonal dimensions of personhood and chronic illness, and the complex impact of DBS on family dynamics, are elided. These renderings, we suggest, could play a significant role in sustaining unrealistic expectations among potential DBS recipients, and indeed among wider publics.

\section{YouTube: digital storytelling \& consuming}

YouTube has been described as a mediated cultural system that has a number of socially important implications (Wyatt et al., 2013; Burgess and Green, 2013). As Burgess and Green (2013) note, the ease with which users can share content on the platform has blurred the line between information production and consumption. Users are able to engage with one another by uploading and commenting on videos, responding to comments, or by emulating stylistic and or compositional elements within their own, amateur-produced videos. One consequence of this has been the emergence of video 'genres' such as the vlog (or video blog), in which users are able to draw on common stylistic elements to craft and manage a public identity while providing an ostensibly honest confession or testimony (Losh and Alexander, 2010). YouTube - along with similar digital platforms - has also enabled a profusion of readily available information. Such information tends to be much more fragmentary and in some cases contradictory than in the past, reflecting the heterogeneous nature of the publics and mediums within which it is produced and consumed (Dwyer, 2010). This proliferation has been accompanied by the emergence of new influential actors that can challenge the traditional purveyors of information. An example of this is the so-called YouTube 'influencers': widely-followed users who review consumer products or services, and whose persuasive power derives from their charisma and the seemingly authentic intimacy of their vlog-style videos (Abidin, 2015, 2016). Influencers are often endorsed and well-paid by industry - a detail which may not be apparent to viewers. This apparent muddling of user and corporate interests, Burgess and Green (2013) note, is another significant feature of the YouTube 'cultural system'.

A significant quantity of the content shared on YouTube relates to healthcare and medicine, and it appears that it has become an important source of information for people seeking healthcare (Harris et al., 2014; Chou et al., 2011; Tian, 2010; Yoo and Kim, 2012). This raises some important questions for those of us exploring the social dimensions of healthcare and medicine. For example, how do users go about delineating health, illness and its treatment, and indeed themselves within YouTube videos? What stylistic and compositional elements do users deploy, and how might these configure the information itself? How are claims about healthcare asserted, and how are 'evidence' and 'authority' enacted? And to what extent are corporate interests of pharma, medical device companies, or health service providers becoming muddled with those of people sharing health-related information? These questions guide our investigation of DBS-related information on YouTube.

Our focus is on those 'amateur' videos that focus on the stories of people receiving DBS for the treatment of Parkinson's. We follow the same vein as the small number of social science studies that have explored health-related narratives on YouTube (Chou et al., 2011; Harris et al., 2016). In his influential The Wounded Storyteller (1995/2013), Arthur Frank illustrates that, when narrating their personal experiences of illness, patients adapt stories that culture 'makes available' to them, and which thus have meaningful resonance with audiences. Because of this, an analysis of narratives can illuminate the dynamics by which illness, identity and sociality can become entwined (Frank, 2013). Studies of healthcare narratives in conventional media have therefore sought to identify how, through the deployment of particular linguistic devices such as plotting, syntax, and evaluation, storytellers delineate themselves and impute causality and moral worth (e.g. Hydén and Brockmeier, 2011). However as Harris et al. (2014) argue, YouTube and other social media platforms allow for new kinds of self-expression: storytellers can deploy not just spoken word and text, but also moving or still images, hyperlinks or other online features to convey meaning and engage audiences. In their study of user narratives of a direct-toconsume genetic testing on YouTube, Harris et al. (2014) note how both spoken and visual elements are combined to convey meaning. They note, for example, the visible setting in which the video has been recorded, the bodily actions of the storyteller and the storytellers' use of props, and their physical engagement with the genetic testing technology.

In this paper, we too explore how both visual and spoken elements are combined within the videos posted by DBS recipients. We are interested in the way in which, collectively, these various elements delineate the DBS recipient, their illness (Parkinson's) and the DBS treatment by foregrounding particular features. What we will illustrate here is that the majority of videos within our study approximate the vlog-style genre of video, while many of the remaining videos have what we refer to as a 'fly-on-the-wall' style. Both styles, via a number of elements, evoke a sense of authenticity and honesty which provide persuasive weight to the unfolding interactions. We argue that the visual framing and spoken elements of the majority of videos foreground the DBS recipient as autonomous while also accentuating Parkinson's as an affliction of the individual. We illustrate how DBS recipients constitute their own bodies as evidence of the effectiveness of DBS by using 
stylistic elements that, we argue, have the capacity to evoke audience responses that are both visceral and cognitive. In light of these features, we draw on Evgeny Morozov's notion of 'techno-solutionism' to argue that the videos involve a powerful "recasting [of] complex social situations ... as neatly defined problems with definite, computable solutions" (Morozov, 2013, 5).

Morozov's criticisms of techno-solutionism broadly align with those of Science and Technology Studies (STS) scholarship on medical technologies that provides the conceptual grounding for this paper (e.g. Timmermans and Berg, 2003; Mol, 2008; Blume, 2009). In particular, the work of both Haddow et al. (2015) and Oudshoorn (2015) has drawn attention to the way in which 'official' narratives surrounding implantable medical technologies tends to obscure the complex relations of care that are needed to sustain the recipients of those technologies. Similarly we argue that, in portraying DBS as a technical fix, YouTube videos elide the relationality of personhood, chronic illness, and its treatment. In this way such videos may indeed contribute to the sustaining of unrealistic expectations among publics and potential DBS recipients. More generally, this demonstrates how YouTube as 'a cultural system' mediates potentially powerful representations of medical technologies that ultimately sustain the ideal of the autonomous, wellbounded individual that underpins much of Western medicine.

\section{Methodology}

The selection and analysis of YouTube videos was undertaken between November 2017 and February 2018. Our intention was to include those videos that someone (such as an individual considering DBS) would likely view if they turned to YouTube for information on DBS as a treatment for Parkinson's disease. Hence, we queried the terms 'Parkinson's' and 'Deep Brain Stimulation', and we selected the sixty most watched amateur (user-created) videos from the search results. Initially, search results contained a mix of mainly amateur, user-created videos, and a few professionally produced promotional videos posted by healthcare providers and medical device manufacturers. While we noted the interspersion of these two video types within search results, the latter were excluded from our final selection of sixty videos so that we could focus on the narratives provided by users themselves. We do, however, reflect on this interspersion of amateur and professional videos in the discussion.

We collected various metadata about the sixty videos that formed our dataset. In addition to the number of views, for each video we noted: the length, the date it was posted, the author, the YouTube categories within which it was posted, the overall tone of the video, the setting (e.g. domestic, clinic), whether the content was filmed live and/ or if it incorporated previously filmed footage, and whether it was 'direct to camera', a filmed interaction involving more than one person, or a mix of these. Following the suggestion of Rose (2007), three of the authors familiarised themselves with the dataset by repeatedly watching a selection of the videos and discussing potential thematic codes before undertaking the analysis. Analysis was undertaken with the assistance of NVivo 10 software with the Ncapture extension (which enables the coding of video footage). This stage was undertaken by author CA, and then independently by author JG, to verify the emerging thematic codes. These were inductively developed following in the manner common to a grounded theory approach (Charmaz, 2014), but while analysing the data, we were also sensitised to those elements which might account for the purported 'high expectations' surrounding DBS. This was reflected in the codes and emerging themes which form the basis of this paper. Following, Harris et al. (2014), our analysis involved carefully examining both visual and aural dimensions of the videos. We took note of how meanings were conveyed via: the visible setting in which the videos appear to be recorded; the visual framing of the videos (who and what is included in the frame?); how individuals within the frame make use of their bodies and/or props as illustrations; and the speech and other noises that accompanied these. In particular, our analysis sought to identify how, via these visual and verbal elements, the DBS therapy and DBS technology were portrayed, how its impact was portrayed, and in the process, how users delineated themselves. In light of the existing studies of news media illustrating that DBS tends to be presented in an overly optimistic light, we were especially attentive to the ways in which such portrayals may elide the complexity of DBS and chronic illness. Hence, we paid close attention to the mention of any negative effects of the intervention, and to how carers and family members were portrayed.

Following Harris et al. (2014), we did not seek informed consent from the individuals who created the 60 videos in our cohort, due to the public accessibility of YouTube and the considerable size of the online community. The videos were therefore treated as online public resources. This was deemed sufficient for our research ethics committee, and the project received ethics approval from a Monash University human research ethics committee. However, it has been noted that research involving social media presents unique ethical challenges and that there is variation among ethics committees and researchers on what counts as 'ethical' conduct (Hibbin et al., 2018). Reflecting on this, and going beyond what was required for ethics approval, we attempted to seek permission from those vloggers whose widely-viewed videos are described as key illustrations in some detail in this paper. We attempted to contact these vloggers via their public profile information on their YouTube channels, but were unsuccessful in all cases. We welcome future discussions on 'ethical best practice' for this grey area of consent when using social media data in this evolving field of research.

\section{Findings}

In February 2018, the average number of views for the videos in the dataset was just under 45,000 . This average was skewed by the mostwatched video, which had been viewed 2.3 million times - significantly more than the second most watched video (just over 116,000 views). The majority of videos had been viewed between 100 and 1000 times. The length of videos ranged from 1:18 to 35:22, and the average length is 6:12. Twenty-six of the sixty videos are posted under category 'People and blogs'; eighteen are posted under 'Science and Technology'; eight are posted under 'Education', and the remaining few are posted under Comedy (4), Auto \& Vehicles (2), 'Film \& Animation' (1), and music (1). All but two of the videos were positive in tone. The two negative videos were from the same user - a recipient whose Parkinson's had not improved with DBS ( 1147 \& 150 views). While some of the positive videos did indeed mention some negative effects of DBS, these mentions tended to be brief, and the overall representation of DBS was highly positive. These representations were conveyed via a number of visual and spoken elements. Below, we illustrate these elements in relation to four common stylistic features: their intimate, authentic settings; the individual-focused framings; the use of juxtaposition; and the use of affective bodily movements.

\subsection{Intimate settings: conveying a sense of authenticity}

As the video begins, we see a room that is clearly domestic: a comfy recliner, a couch with soft furnishings, a coffee table and rug, house plants, and framed pictures all indicate a living room. A voice-over announces: "Today is the 13th of November 2010. One year ago on this date, I was in the operating theatre at [medical centre] for deep brain stimulation." A middle-aged man then walks into the frame and stands directly in front of the fixed camera, looking directly at the viewer .... (Video 3, over 115,000 views).

This extract is typical of the majority of videos. forty-five of the videos were recorded in what appear to be domestic settings: livings rooms, studies, and in a couple of cases, kitchens or bedrooms. Common domestic furnishings such as cushions and rugs, and personal items 
such as framed pictures, are often clearly visible, and the living rooms in particular have the appearance of being spaces that are well-used. As the above extract illustrates, vloggers in these domestic settings look directly at the camera while introducing themselves and stating that they are receiving DBS. The verbal content appears to be unscripted, and the videos in this style have an amateurish feel to them.

These domestic settings and style of direct engagement with the audience create a sense of liveness and immediacy. Via the camera, the audience is, in effect, brought into the personal and usually private space of the DBS recipient, and the audience is directly beckoned into a 'face-to-face' interpersonal interaction with the recipient. In these ways the videos replicate the video diary blog, or 'vlog', that is common to many YouTube videos, particularly coming-out vlogs, and those of 'influencers' (Losh and Alexander, 2010; Abidin, 2015). The persuasive power of this style derives from their direct engagement with the audience, creating the sense that we, as the audience, are witnessing a genuine account of the vlogger's experiences or feelings from the comfort and safety of the vlogger's personal space (Matthews, 2007). In these DBS vlogs, the domestic setting, the direct address to the camera, and the amateurish quality give the impression that we the audience are witnessing a health care consumer's authentic, unpolished and unmediated account of the DBS therapy.

The majority of the remaining videos (8) were filmed in what appear to be clinical settings. These are exemplified by the following extract:

The unsteady, moving frame suggests that the camera is being held by someone. In the centre of the frame is a young woman, seated on an adjustable clinical bench draped with a disposable paper sheet. There are clinical tools and sockets fixed to the wall behind the women. These things, along with the white wall and light-coloured hard floor suggest that this is a consultation room. The women is smiling at a clinician who is out of frame, and who is instructing the women to move her limbs in particular ways to illustrate her tremor. Subsequently, the interaction between the women, the clinician and the camera operator reveals that the women has recently had the DBS system implanted, and that it is currently switched off. It is later turned on, with results that appear to generate considerably joy among those in the room, including the camera operator ... (Video 7 , approximately 17,000 views)

In these videos, the DBS recipient is having their DBS system programmed by a health professional seemingly for the first time. The recording has been made by a third person, probably a family member, who in many cases verbally communicates with the recipient, and who, along with the recipient, expresses obvious delight at the effect of DBS as it is programmed by the professional. Again, the amateur quality of these videos and the unscripted nature of the interaction give them a sense of authenticity. This is heightened by their seemingly raw emotional quality: in several videos, the DBS recipient and camera operator can be seen or heard to sob with joy. The 'fly-on-the-wall' audience is thus given the sense that we are privy to an authentic clinical encounter that would usually be confidential.

The intimate settings and mode of audience engagement of both the vlog style and the 'fly-on-the-wall' style thus produces a sense of authenticity, albeit in different ways. We suggest that this endows them with considerable persuasive power as 'true' accounts of DBS and its impact of Parkinson's disease. Via the camera, we the audience bear witness to a recipient's first-hand experiences of DBS, seemingly unmediated by, for example, medical device manufacturers, health professionals, or some other actor with vested interests. We now explore more closely how exactly the recipient delineates themselves and their illness.

\subsection{Composition: accentuating the individual}

The only person to appear in the majority of videos (i.e. all of those that we have referred to as vlog-style videos), are the DBS recipients themselves. In most cases, the video is positioned in such a way that the frame is occupied predominately by the upper body and face of the recipient, and in some cases, the full body of the recipient as they stand directly in front of the camera. We the audience see, then, the recipient close-up, in their domestic setting, alone. This individual-oriented framing, we argue, foregrounds the impact of Parkinson's disease - and the impact of the DBS intervention - on the individual.

This foregrounding of the individual also occurs via the use of various spoken narrative elements. In the vlog-style videos, vloggers provide some sort of verbal account of the impact of Parkinson's disease, followed by an account of the effect of DBS (which, as we illustrate in the next section, is often accompanied by a dramatic demonstration). Typically, the detrimental impact of Parkinson's disease is described in terms of well-known motor symptoms such as tremor (shaking), rigidity, an expressionless face ('face drop'), and speech issues: "My legs are shaking pretty bad. My trunk. My whole body now is tremoring. It is even effecting my voice a little bit" (Video 13 views). In most videos, then, Parkinson's disease is delineated as a dramatic affliction of the individual's body. Additionally, in providing these verbal accounts, vloggers almost exclusively refer to the impact of these symptoms on themselves, and it is common for vloggers to make no mention of anyone else - specifically or generally - throughout the video. The following extract illustrates this individual-focused description of Parkinson's.

'I have a scale of 1-10 ... If it's a 2 or 3, I'm not impacted much - it's a negative impact scale. If it's a 7 I'm incapacitated and I can't function at the computer. 'If it's a 6 or a 5, things are bad but I can still operate (Video 4, 3589 views)

As this extract also illustrates, references were often made to particular individual-orientated activities such as using a computer. Vloggers commonly described Parkinson's as impeding their ability to walk, to feed themselves, and to stand up from a seated position. Many vloggers also make reference to the impact on their capacity to 'work', but this is mentioned in a general fashion without reference to any interpersonal activities or relations.

By delineating themselves and Parkinson's disease in these ways, the DBS recipients accentuate their independence and autonomy. Among the vlog-style videos were some exceptions, as several DBS recipients briefly mentioned family members. One vlogger concludes that Parkinson's diseases has had “... a major effect on my life, and a major effect on my family's life which is the main thing" (Video 1, 2.2 million views), although this is his only reference to the interpersonal dimensions of his illness. Another blogger laments that Parkinson's disease means that he cannot be a normal dad for his children, and that his wife has provided him with wonderful emotional support (Video 15, 807 views). On the whole, however, we argue that the relational dimensions of illness, and the impact of chronic illness on family members, are largely elided by both the visual and spoken narrative components of the vlog-style videos.

Among the remainder of the videos $(n=15)$, the relationality of the DBS recipient and their chronic illness are evoked in a number of ways. The fly-on-the-wall style videos $(n=8)$ involve very little or no spoken references to the impact of Parkinson's on the family or friends, but the presence of other people within the video frame, and in particular the emotional response of the camera operator to the clinical interaction, allude to the interpersonal dimensions of Parkinson's disease and its treatment. Among the remainder of the videos, however, is one amateur 'documentary style' video, in which the DBS recipient and several family members are interviewed about the impact of Parkinson's and DBS on family life. This unique video among the data cohort primarily delineates Parkinson's as an affliction that affects families, and it stands in stark contrast to the majority of films. At one point, during a montage of family portraits and historical family footage, the DBS recipient states that 'Parkinson's disease effects both the mind and the body, and those 
of family and friends too'. This is followed shortly after with the recipient's son saying "... [the disease] brought the family closer" (Video $40,10,000$ views).

\subsection{Before/after, on/off: demonstrating the effect of DBS}

Seated and looking directly at the camera, the vlogger continues: [DBS] is a procedure whereby two probes are dropped deep into my brain and hooked up via a wire down my neck to a pacemaker in my chest. This provides a steady stream of electricity to my brain. (Video 1, 2.2 million views).

Here we see an example of how DBS is commonly described by vloggers within the vlog-style videos. Generally, mention is made of the pacemaker (or IPG, implantable pulse generator), the 'wires' that run from the 'pacemaker', the 'leads that penetrate deep into the brain', and the 'steady stream' or constant flow of 'electricity' that is delivered deep within the brain. Such descriptions present DBS as mechanistic and technical intervention for a mechanical, malfunctioning individual brain (In this regard, these descriptions also reflect the biomedicallyoriented descriptions for lay-persons found in public-facing information of health service providers and device manufacturers). Several videos also include brief clips of what appear to be appropriated, professionally produced animations of DBS, which illustrate the positioning of the components within the body and the transfer of electricity from the IPG to areas deep within the brain.

The mechanistic, technical dimension of DBS is also accentuated by other features. In the vlog-style videos, after describing the DBS, many vloggers reveal the remote DBS programmer to the audience. This often happens as they state the main purpose for their vlog:

Today I would like to show you what happens when I turn the neurostimulator off ... To show you the dramatic effect I will demonstrate. This is me with the power on. He holds his arms out directly in front of him, and rapidly repeats clasping his fingers to his thumbs ... these are tests that the neurologists make us do to test our reflexes. As you can see ... they are moving fine. He then holds a small device with a digital display in front of the camera, and then places it against his chest and pushes a few buttons ... This is the remote control and this checks that I'm on. The device makes a loud 'beep!' On and okay. And this is me when I turn it off .... He holds the device up to the camera. You won't be able to read that I'm shaking too much. It's almost an instantaneous reaction. I can't control this. As he holds his arms out in front of him as before: You could shake some quality cocktails with the right [hand] ... My voice is ggg-gone it is harder for me speak and ggg-get words out, I'm completely rigid and if I tried to stand up I would fall ... I ccc-cant control the tremors ... the twisting in my neck is called dystonia. As you can see the tremors are getting much worse ... So I think party time is over. He places the remote programmer over the chest and pushes a button. Almost automatically. The power comes back ... If anyone is considering DBS, I thoroughly recommend it. (Video 1, 2.2 million views).

Using the visible remote programmer, vloggers such as this recipient provide a graphic demonstration of the therapeutic impact of DBS. With a self-administered adjustment to the visible programmer (which looks like a small TV remote), their body quickly transforms from being perceivably calm and controlled, to being afflicted with violently shaking or rigidly contorted limbs and postures and stuttered speech. And, with a second, self-administered adjustment to the programmer, the afflicted body reverts to its previous calm and composed state. The symptoms of Parkinson's, and the impact of DBS of Parkinson's are thus dramatically portrayed. As this happens, the mechanistic, technical dimension of DBS is foregrounded, particularly by the demonstration of its programmability with a remote device. The visible use of the remote device, which appears to permit the recipient to control the therapeutic effect of DBS, again accentuates the recipient's autonomy. In the process of turning the device off/on, DBS is portrayed as an extremely effective and uncomplicated intervention for Parkinson's.

Another common way in which the effect of DBS is demonstrated is via the juxtaposition of 'before and after DBS' footage. In some cases, the juxtaposition is sequential: several vlog style videos are edited so that before and after footage are shown immediately one after the other. In one example, a middle-aged man narrates to the camera as he very slowly and with great difficulty stands-up from his chair and shuffles to a nearby doorway. This is followed by footage of the same man walking briskly and confidently along the street, smiling directly at the camera (Video 35, 188 views). In other examples, before and after footage is juxtaposed within a split screen frame, one immediately adjacent to the other. As with the on/off vlogs, in both modes of juxtaposition an afflicted, disordered body provides a perfect and immediate reference for the post-DBS body, and the impact of the DBS is rendered as dramatic, obvious, and individual-orientated. As the extract above illustrates, this is often accompanied by a highly positive verbal appraisal or recommendation: If anyone is considering DBS, I thoroughly recommend it (Video 1, 2.2 million views).

\section{Persuasive bodies}

The visible body, therefore, is configured as primary evidence of DBS's effectiveness within recipients' testimony. In this section, we examine these configurations of bodies-as-evidence in more depth - we suggest that several common features may induce a sense of bodily empathy with audiences, thus heightening their persuasive power. The premise of our claim here is that "belief ... [is] intimately bound up with affect, and dependant on the somatic dispositions" (Gibbs, 2011). The persuasive power of visual media, scholars have argued, derives from its capacity to evoke responses that are both visceral and cognitive, often by directly portraying bodies in states that recall associated feelings and thoughts among audiences (Connolly, 2011; Bourdieu, 1990).

In several of the most-viewed on/off vlog-style video (including the most-viewed video with 2.2 million views) there is one element in particular that induced a strong embodied response within us as we undertook the analysis. Within several seconds of turning the DBS device on again, the recipients exhale a large, audible sigh, just as their shaking, tense and contorted bodies relaxes into their 'DBS-on' calm state. The exhalation appears to express a strongly felt sense of relief as the body dramatically transforms from what several describe as painful or deeply uncomfortable tension. Watching vloggers voluntarily experience the full brunt of their Parkinson symptoms on camera often caused us, as viewers, to grow tense; similarly, the sigh, an expression that we all have our own embodied experience of, induced a sense of bodily relief in ourselves. It provided a visceral empathic relatability that attuned us - albeit in a momentary and superficial way - to the bodily relief experienced by the patient. In this sense, we as viewers felt the therapeutic effect of DBS. This, we suggest, is illustrative of the potentially powerful affective dimensions of vlog-style videos, which provide them with considerable persuasive power. Similarly, a powerful affective element in the fly-on-the-wall style videos is the seemingly authentic sense of joy experienced by DBS recipients and their accompanying family members as the DBS device is turned-on for the first time. As noted above, the joy is sometimes accompanied by audible sobbing and emotive verbal statements.

DBS recipients also configure their bodies-as-evidence in more deliberate, instrumental ways. In order to demonstrate the difference between on/off or before/after DBS, the recipients will often perform particular tasks in both states. In many cases, this involves techniques appropriated from neurology: many recipients perform hand and finger movement tasks that are components of standardised neurology examinations and which would be familiar to people with chronic neurological conditions. Many participants also demonstrate their walking ability. Others perform mundane, domestic tasks to demonstrate the 
effectiveness of DBS in the context of their day-to-day lives. This often involves using various domestic objects as props. Several participants used eating as a way of contrasting before/after or on/off. One video, for example, begins with footage of the recipient sitting at a dining table attempting - with great difficulty - to eat cereal from a bowl with a spoon. This is followed by footage of the same recipient carving a Christmas ham with a large knife, with carefully-set dinner table visible behind him (Video 9, 258 views). In another video, a recipient turns off his DBS device and picks up a glass of water laden with ice cubes, which begins to rattle loudly and spill on the table before him (Video 11, 8,360 views). Such demonstrations enable the audience to directly witness how Parkinson's, and hence DBS, impact the individual's ability engage in everyday domestic tasks - tasks that would be familiar to the audience. The therapeutic impact of DBS, in other words, is conveyed using specific, visually verifiable frames of reference that audience members can easily understand. We suggest that this also facilitates a sense of empathy, as it permits audience members themselves to more concretely imagine life with Parkinson's and indeed the need of DBS.

\section{Discussion: the atomistic individual and the myth of technological solutionism}

\section{Evgeny Morozov has defined technological solutionism as:}

[The] recasting [of] complex social situations either as neatly defined problems with definite, computable solutions or as transparent and self-evident processes that can be easily optimised - if only the right [technologies] are in place $(2013,5)$.

It has, Morozov argues, become a defining feature of the hype that surrounds new technologies, especially digital technologies, in contemporary Western societies. We suggest, however, that the term can aptly be used to describe the portrayals of DBS in YouTube videos. A key dimension of technological solutionism, according to Morozov's definition, is the elision of complexity: social phenomena are bracketed as discrete, intelligible problematics; technologies are delineated as well-bounded interventions with predictable effects; and the effects themselves are presented as clearly discernible and advantageous. By far the majority of YouTube videos examined here do precisely this.

First, the illness itself, Parkinson's disease, is presented as a set of relatively clear-cut, severe bodily symptoms - rigidity, shaking limbs, an expressionless face - that impede a person's ability to perform relatively straightforward tasks. Various complexities are elided from such representations, such as the differences in disease presentation between people and the differences in people's experience of the disease. Indeed, other representations of Parkinson's disease foreground the deep sense of uncertainty that it presents for people and their clinicians: Parkinson's is idiopathic, and unpredictable in its progression (Warren and Ayton, 2018). Various other symptoms, such as postural instability, gait problems and cognitive decline (none of which respond to DBS) are also elided from the videos, as are, most importantly, the relational, interpersonal dimensions of the disease such as its impact on spouses and family members. Parkinson's disease, in other words, is enacted as a clearly defined set of treatable problems that affect an individual.

Second, the DBS intervention itself is presented as a well-bounded technological intervention. It is described by participants in mechanistic terms as a system of physical components that operate in a deterministic manner on the afflicted brain. Its 'technological' nature and deterministic operation are foregrounded by the visibility of a remote programmer, and by the apparent ease with which recipients use the programmer to turn the device off/on and transform from a well/notwell bodily state. Again, this enactment involves the elision of various relational, interpersonal dimensions. While some vloggers mentioned that they had their DBS system readjusted by clinicians, the majority DBS videos seldom mention that DBS-recipients become reliant on specialist clinical teams to reprogram and manage the DBS system as the underlying illness progresses - an aspect that DBS recipients elsewhere have lamented (Gisquet, 2008). The possibility of the DBS technology malfunctioning (as with all medical technology), also goes unrepresented in these videos: surgical wounds can become infected, leads can become damaged, and electrodes can become dislodged (Fenoy and Simpson, 2014). However these are not the stories of DBS that are captured in Vlogs. They also neglect to mention the potential impact of DBS on mood, and particularly its capacity for inducing mania, impulsive behaviours, or a sense of self-estrangement (see Gilbert, 2018; Gilbert et al., 2017), which can cause considerable emotional stress for families (Gisquet, 2008). Indeed, the impact of DBS on spouses and families is barely mentioned in the majority of videos. And third, those impacts of DBS that are foregrounded - its impact on specific physical symptoms of Parkinson's - are presented in the videos as being clearly discernible and most certainly advantageous. The juxtaposition of the controlled body with the afflicted body does this dramatically, as does the emotional, joyful reactions of recipients and their family members in the 'fly-on-the-wall' style of videos. Hence, overall DBS is enacted as a technological fix: it is a well-bounded and effective technological intervention for a clearly delineable problem.

In the process, the relational dimensions of the afflicted person are elided - in the majority of videos they are presented as an autonomous, atomistic individual. What we see here, then, is how the vernacular stylistic elements of YouTube videos result in representations of medical technologies that perpetuate the ideal of the well-bounded individual. This influence of this ideal on healthcare practices has been well-characterised and criticised by scholars as the 'tyranny of autonomy' in Western medicine (e.g. Foster, 2009; Fox and Swazey, 2008; Prainsack, 2017). Broadly, the ideal valorises a form of personhood in which people are highly independent and strategically rational, and in which their actions are measurable and predictable (Prainsack, 2017). Regulatory, legal and bioethical frameworks in healthcare have been criticised for reifying this form of personhood (Fox and Swazey, 2008; O'Neill, 2003), as has much of the public discourse championing greater 'patient choice' in healthcare (Mol, 2008; Cribb, 2011). Much of the enthusiasm for implantable medical technologies, as Haddow et al. (2015) suggest, also reflects this valorisation of the well-bounded individual: recipient 'cyborgs' are envisaged as having greater autonomy from burdensome networks of care. Here, we see how a social media platform has enabled healthcare users themselves to participate in sustaining this expectation, even if the day-to-day experiences of Parkinson's and DBS are much more complex.

We have also suggested that specific compositional elements of these videos may mean that the representations of DBS are especially persuasive to audiences. The domestic settings of the vlog-style videos, and the clinical settings of the 'fly-on-the-wall' style videos, give them a sense of authenticity: we, the, audience, are watching an unmediated account of DBS. In this regard, the vlog-style videos emulate the confessional or testimonial style vlogs that are common to the internet (Burgess and Green, 2013). The dramatic juxtaposition of the afflicted, disordered body with the DBS-stimulated body is a stark visual reference, and recipients' use of common props and everyday domestic tasks to demonstrate the impact of DBS provides clear-cut frames of reference that viewers themselves can relate to. We have also suggested that the audible sigh of relief of participants as their body transforms from one state to the other is an especially affective feature. It could prompt, we suggest, an embodied sense of relatability among viewers that momentarily attunes them to the therapeutic relief experienced by recipients.

In their study of health-related YouTube videos, Harris et al. (2014) note amateur-produced videos can advance corporate interests by providing a form of advertising. This can certainly apply to the amateur videos studied here: These potentially powerful, amateur-created representations of DBS are circulated and consumed within a medium that configures them to serve corporate interests. YouTube search results generally make no distinction between video created by amateur 
users and those created by corporate entities. As noted above, the search results here produced mostly amateur uploaded videos, interspersed with a few professionally produced videos. Several of these latter videos were advertisements for specific specialist DBS services produced by private health care providers such as Mount Sinai. Several videos have also been posted by DBS device manufacturers, such as Medtronic, one of which uses 'before \& after' juxtaposition to illustrate the dramatic effect of DBS. Because of this, DBS information-seeking viewers would be exposed concurrently to the persuasive, seemingly authentic and personal accounts of DBS users, and to polished, commercially-orientated accounts of corporate entities. Viewers' engagement with the latter could, in effect be primed by affective dimensions of the former. We see here, then, how amateur-produced videos can lend themselves to corporate interests within what Burgess and Green (2013) describe as the 'YouTube 'cultural system'.

Currently, there is no research on the degree to which people seeking information on DBS for Parkinson's disease actually engage with YouTube videos, and determining whether such videos are as persuasive as we hypothesise here would require additional research that includes viewers themselves. Nevertheless, our findings do illustrate how social media platforms can become implicated in perpetuating promissory representations of medical technologies and healthcare interventions (see Brown et al., 2000; Borup et al., 2006). The intersection of YouTube and its vernacular stylistic conventions with patient narratives and afflicted bodies has resulted in an overwhelmingly positive portrayal of the technology. While for some recipients of DBS this is indeed the case, many of the complexities about the DBS intervention are lost. We can see here then how the YouTube portrayals can, alongside the hyped portrayals within conventional media (Racine et al., 2007), sustain unrealistic expectations about the capacity of medical technology among DBS recipients, and indeed among publics more generally. There is very likely a selection bias underlying this corpus, as recipients who have less striking or positive results from their procedure may be less likely to turn to mediums such as YouTube to broadcast their experiences.

\section{Acknowledgements}

We would like to thank Dr Brady Robards for his guidance, and the anonymous reviewers for their valuable feedback.

\section{References}

Abidin, Crystal, 2015. Communicative $\bullet$ intimacies: influencers and perceived interconnectedness. Ada: J. Gender, New Media Technol. 8.

Abidin, Crystal, 2016. "Aren't these just young, rich women doing vain things online?": influencer selfies as subversive frivolity. Soc. Media + Soc. 2 (2). https://doi.org/10. 1177/2056305116641342. 2056305116641342

Agid, Y., Schüpbach, M., Gargiulo, M., Mallet, L., Houeto, J.L., Behar, C., Maltete, D., Mesnage, V., Welter, M.L., 2006. Neurosurgery in Parkinson's disease: the doctor is happy, the patient less so? J. Neural. Transm. 70 (Suppl. 1), 409-414.

Bell, E., Mathieu, G., Racine, E., 2009. Preparing the ethical future of deep brain stimulation. Surg. Neurol. 72 (6), 577-586. https://doi.org/10.1016/j.surneu.2009.03. 029. discussion 586.

Bell, Emily, Maxwell, Bruce, McAndrews, Mary Pat, Sadikot, Abbas F., Racine, Eric, 2011. A review of social and relational aspects of deep brain stimulation in Parkinson's disease informed by healthcare provider experiences. Parkinson's Dis. 2011, 8. https://doi.org/10.4061/2011/871874.

Blume, S., 2009. The Artificial Ear: Cochlear Implants and the Culture of Deafness. Rutgers University Press.

Borup, Mads, Brown, Nik, Konrad, Kornelia, Van Lente, Harro, 2006. The sociology of expectations in science and technology. Technol. Anal. Strat. Manag. 18 (3-4), 285-298. https://doi.org/10.1080/09537320600777002.

Bourdieu, P., 1990. The Logic of Practice. Stanford University Press.

Brown, N., Rappert, B., Webster, A., 2000. Contested Futures: a Sociology of Prospective Techno-science. Ashgate.

Burgess, J., Green, J., 2013. YouTube: Online Video and Participatory Culture. Policy, Cambridge UK.

Charmaz, K., 2014. Constructing Grounded Theory. SAGE Publications.

Chou, W.Y., Hunt, Y., Folkers, A., Augustson, E., 2011. Cancer survivorship in the age of YouTube and social media: a narrative analysis. J. Med. Internet Res. 13 (1), e7. https://doi.org/10.2196/jmir.1569.
Connolly, W.E., 2011. A World of Becoming. Duke University Press.

Cribb, Alan, 2011. Involvement, Shared Decision-making and Medicines. Royal Pharmaceutical Society, London.

Dwyer, T., 2010. Media Convergence. McGraw Hill/Open University Press.

Eggington, S., Valldeoriola, F., Chaudhuri, K.R., Ashkan, K., Annoni, E., Deuschl, G., 2014. The cost-effectiveness of deep brain stimulation in combination with best medical therapy, versus best medical therapy alone, in advanced Parkinson's disease. J. Neurol. 261 (1), 106-116. https://doi.org/10.1007/s00415-013-7148-z.

Fenoy, A.J., Simpson Jr., R.K., 2014. Risks of common complications in deep brain stimulation surgery: management and avoidance. J. Neurosurg. 120 (1), 132-139. https://doi.org/10.3171/2013.10.Jns131225.

Foster, C., 2009. Choosing Life, Choosing Death: the Tyranny of Autonomy in Medical Ethics and Law. Bloomsbury Publishing.

Fox, R.C., Swazey, J.P., 2008. Observing Bioethics. Oxford University Press.

Frank, A.W., 2013. The Wounded Storyteller: Body, Illness, and Ethics, second ed. University of Chicago Press.

Gardner, J., 2017. Rethinking the Clinical Gaze: Patient-centred Innovation in Paediatric Neurology. Palgrave Macmillan, Basingstoke UK.

Gardner, John, Samuel, Gabrielle, Williams, Clare, 2015. Sociology of low expectations. Sci. Technol. Hum. Val. 40 (6), 998-1021. https://doi.org/10.1177/ 0162243915585579 .

Gardner, John, Warren, Narelle, 2018. Learning from deep brain stimulation: the fallacy of techno-solutionism and the need for 'regimes of care'. Med. Healthc. Philos. https://doi.org/10.1007/s11019-018-9858-6.

Gibbs, Anna, 2011. Affect theory and audience. In: NIghtingale, Virginia (Ed.), The Handbook of Media Audiences. Wiley-Blackwell, Hoboken NJ, pp. 251-266.

Gilbert, F., 2012. The Burden of Normality: from 'chronically ill' to 'symptom free' New ethical challenges for deep brain stimulation postoperative treatment'. J. Med. Ethics 38 (7), 408-412.

Gilbert, F., 2018. Deep Brain stimulation: inducing self-estrangement. Neuroethics 11 (2), 157-165.

Gilbert, F., Goddard, E., Viana, J.N.M., Carter, A., Horne, M., 2017. I miss being me: phenomenological effects of deep brain stimulation,Am. J. Bioeth. Neurosci. 8 (2), 96-109.

Gilbert, Frédéric, Ovadia, Daniela, 2011. Deep brain stimulation in the media: over-optimistic portrayals call for a new strategy involving journalists and scientists in ethical debates. Front. Integr. Neurosci. 5, 16. https://doi.org/10.3389/fnint.2011. 00016.

Gisquet, E., 2008. Cerebral implants and Parkinson's disease: a unique form of biographical disruption? Soc. Sci. Med. 67 (11), 1847-1851. https://doi.org/10.1016/j. socscimed.2008.09.026.

Haddow, Gill, King, Emma, Kunkler, Ian, Duncan, McLaren, 2015. Cyborgs in the everyday: masculinity and biosensing prostate cancer. Sci. Cult. 24 (4), 484-506. https://doi.org/10.1080/09505431.2015.1063597.

Harris, A., Kelly, S., Wyatt, S., 2016. CyberGenetics: Health Genetics and New Media. Taylor \& Francis.

Harris, Anna, Kelly, Susan E., Wyatt, Sally, 2014. Autobiologies on YouTube: narratives of direct-to-consumer genetic testing. New Genet. Soc. 33 (1), 60-78. https://doi.org/ 10.1080/14636778.2014.884456.

Hibbin, R.A., Samuel, G., Derrick, G.E., 2018. From "a fair game" to "a form of covert research": research ethics committee members' differing notions of consent and potential risk to participants within social media research. J. Empir. Res. Hum. Res. Ethics 13 (2), 149-159. https://doi.org/10.1177/1556264617751510.

Hydén, L.C., Brockmeier, J., 2011. Health, Illness and Culture: Broken Narratives. Routledge.

Losh, Elizabeth, Alexander, Jonathan, 2010. "A YouTube of one's own?": "coming out" videos as rhetorical action. In: Pullen, Christopher, Cooper, Margaret (Eds.), LGBT Identity and Online New Media. Routledge, New York, pp. 23-36.

Lupton, D., 2017. Digital Health: Critical and Cross-disciplinary Perspectives. Taylor \& Francis.

Matthews, Nicole, Confessions to a new public: Video Nation Shorts, 2007. Media Cult. Soc. 29 (3), 435-448, https://doi.org/10.1177/0163443707076184.

Mol, A., 2008. The Logic of Care: Health and the Problem of Patient Choice. Routledge.

Morozov, E., 2013. To Save Everything, Click Here: the Folly of Technological Solutionism: PublicAffairs.

O'Neill, O., 2003. Some limits of informed consent. J. Med. Ethics 29 (1), 4-7. https://doi. org/10.1136/jme.29.1.4.

Okun, Michael S., 2014. Deep-brain stimulation - entering the era of human neuralnetwork modulation. N. Engl. J. Med. 371 (15), 1369-1373. https://doi.org/10. 1056/NEJMp1408779.

Oudshoorn, Nelly, 2015. Sustaining cyborgs: sensing and tuning agencies of pacemakers and implantable cardioverter defibrillators. Soc. Stud. Sci. 45 (1), 56-76. https://doi. org $/ 10.1177 / 0306312714557377$.

Pietzsch, J.B., Garner, A.M., Marks Jr., W.J., 2016. Cost-effectiveness of deep brain stimulation for advanced Parkinson's disease in the United States. Neuromodulation 19 (7), 689-697. https://doi.org/10.1111/ner.12474.

Prainsack, Barbara, 2017. The "we" in the "me": solidarity and health care in the era of personalized medicine. Sci. Technol. Hum. Val., 0162243917736139. https://doi. org/10.1177/0162243917736139.

Racine, E., Waldman, S., Palmour, N., Risse, D., Illes, J., 2007. "Currents of hope": neurostimulation techniques in U.S. and U.K. print media. Camb. Q. Healthc. Ethics 16 (3), 312-316.

Racine, Eric, Waldman, Sarah, Rosenberg, Jarett, Illes, Judy, 2010. Contemporary neuroscience in the media. Soc. Sci. Med. 71 (4), 725-733. https://doi.org/10.1016/j socscimed.2010.05.017.

Rose, G., 2007. Visual Methodologies: an Introduction to the Interpretation of Visual 
Materials. SAGE Publications.

Santos, Dos, Joao Flores Alves, du Montcel, Sophie Tezenas, Gargiulo, Marcella, Behar, Cecile, Montel, Sébastien, Hergueta, Thierry, Navarro, Soledad, Hayat, Belaid, Cloitre, Pauline, Karachi, Carine, Mallet, Luc, Welter, Marie-Laure, 2017. Tackling psychosocial maladjustment in Parkinson's disease patients following subthalamic deep-brain stimulation: a randomised clinical trial. PLoS One 12 (4), e0174512. https://doi.org/10.1371/journal.pone.0174512.

Schüpbach, M., Gargiulo, M., Welter, M.L., Mallet, L., Behar, C., Houeto, J.L., Maltete, D., Mesnage, V., Agid, Y., 2006. Neurosurgery in Parkinson disease: a distressed mind in a repaired body? Neurology 66 (12), 1811-1816. https://doi.org/10.1212/01.wnl. 0000234880.51322 .16 .

Tian, Y., 2010. Organ donation on Web 2.0: content and audience analysis of organ donation videos on YouTube. Health Commun. 25 (3), 238-246. https://doi.org/10. 1080/10410231003698911.
Timmermans, Stefan, Berg, Marc, 2003. The practice of medical technology. Sociol. Health Illness 25 (3), 97-114. https://doi.org/10.1111/1467-9566.00342.

Warren, N., Ayton, D., 2018. Re)negotiating normal every day: phenomenological uncertainty in Parkinson's disease. In: Thomas, Gareth, Sakellariou, Dikaios (Eds.), Disability, Normalcy and the Everyday. Routledge, New York.

Wyatt, Sally, Bier, Jess, Harris, Anna, Bas van Heur, 2013. Participatory knowledge production 2.0: critical views and experiences. Inf. Commun. Soc. 16 (2), 153-159. https://doi.org/10.1080/1369118X.2012.746382.

Wyatt, S., Henwood, F., Hart, A., Smith, J., 2005. The digital divide, health information and everyday life. New Media Soc. 7 (2), 199-218. https://doi.org/10.1177/ 1461444805050747.

Yoo, J.H., Kim, J., 2012. Obesity in the new media: a content analysis of obesity videos on YouTube. Health Commun. 27 (1), 86-97. https://doi.org/10.1080/10410236.2011. 569003. 